History

\title{
History of the Plastic Surgery department at Lokmanya Tilak Municipal Medical College and General Hospital at Sion, Mumbai
}

\author{
A. D. Dias, M. R. Thatte \\ Consultant Plastic Surgeons and Ex staff members of the Department
}

Address for correspondence: M. R. Thatte, Vimal Smruti, 770, Dr. Ghanti Road, Dadar, Mumbai - 400014 , India. E-mail: mthatte@vsnl.com

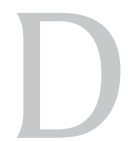

r. A. D. Dias and Dr. R. L. Thatte established the Department of Plastic Surgery at Sion Hospital in 1979 and the rest as they say is history. It is this history that we attempt to narrate here. There will inevitably be gaps and omissions, for no narrator is perfect. For these possible lapses we crave your indulgence for they are unintentional and inadvertent. The use of the first person by the chroniclers has been retained as it adds to the feeling of a story being told in the best of India's oral tradition with love and affection.

The development of a department is a process of evolution and that evolution is still taking place. The Department of Plastic Surgery at the Lokmanya Tilak Municipal Medical College and General Hospital (Sion Hospital) was sanctioned by the municipal commissioner on 20.12.1977. I (ADD) was appointed as Hon. Plastic Surgeon and Hon. Prof. of Plastic Surgery on 01.01.1978 and the department took concrete shape after about 1$1 \frac{1}{2}$ years.

We were initially housed in what was originally the military hospital and barracks. These were single storied structures of brick and mortar with tiled roofs [Figure 1]. There was lots of space, fresh air and verdant surroundings. We were living in true communion with nature, with plenty of trees, grass, cattle, cats, dogs, serpents and other creepy and crawly elements around us. But is was very peaceful and relaxing, particularly after a hard days' work.
In the field of surgery there were the general surgery department, and ophthalmic and ENT sections. I worked as a senior registrar with my colleague late Dr. M. N. Gheewalla and under a full time chief surgeon, late Dr. S. H. Chitnis. Dr. S. V. Joglekar was our superintendent. They were all extremely helpful, dynamic and forward looking.

As the hospital had plenty of space and a large volume of patients, we already had teaching status when I joined the hospital. The BYL Nair Hospital was able to admit a larger number of students as these students were sent to Sion Hospital for training!

There were several criminal gangs and smugglers in and around Sion. So we had plenty of stab wounds and other injury cases. Surgical work was plentiful, wide and varied. (later members named it the 'Gun and Knife Club' of Dharavi which ensured great experience in Hand and micro work for them).

However, the desire for excellence and creativity slowly veered me towards plastic surgery. I had done my graduation, post graduation and several other residential posts at the Seth GS Medical College and King Edward VII ${ }^{\text {th }}$ Memorial hospital. But coming to Sion was exciting as it gave me the opportunity to create a new department and play a role in its function. There were plenty of Plastic Surgery cases at Sion Hospital. Hence I felt that my training in plastic surgery should not be just theoretical, but also practical. With great help from 


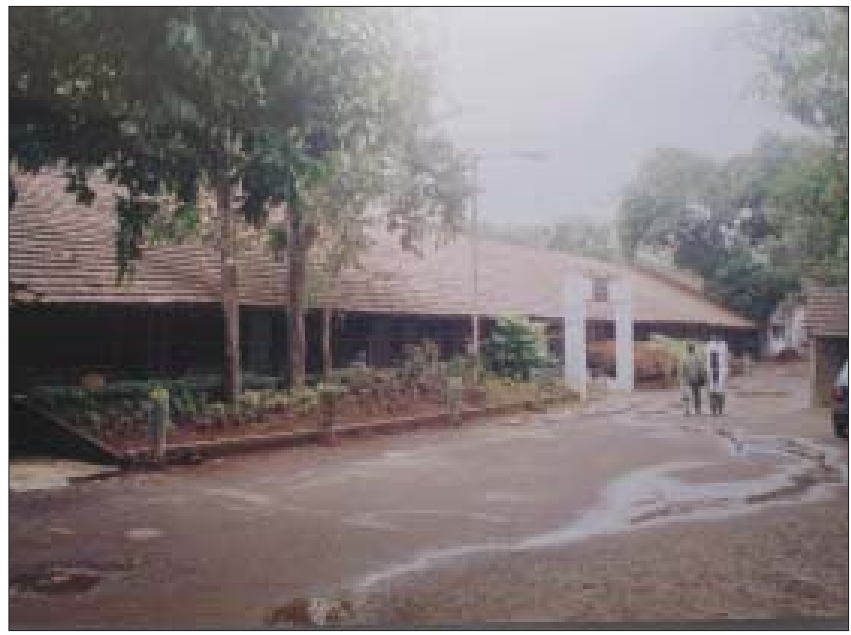

Figure 1: The 'old barracks' which formed the first wards of Dr. A. D. Dias

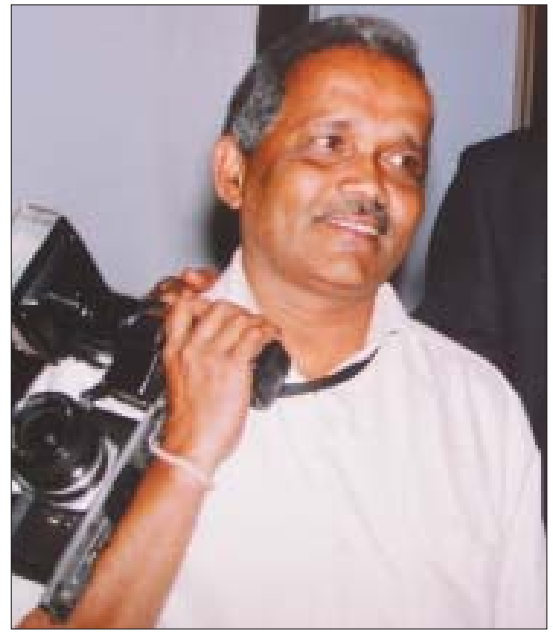

Figure 2: Mr. P. S. Pangerkar also called 'Parshu'-a legendary photographer

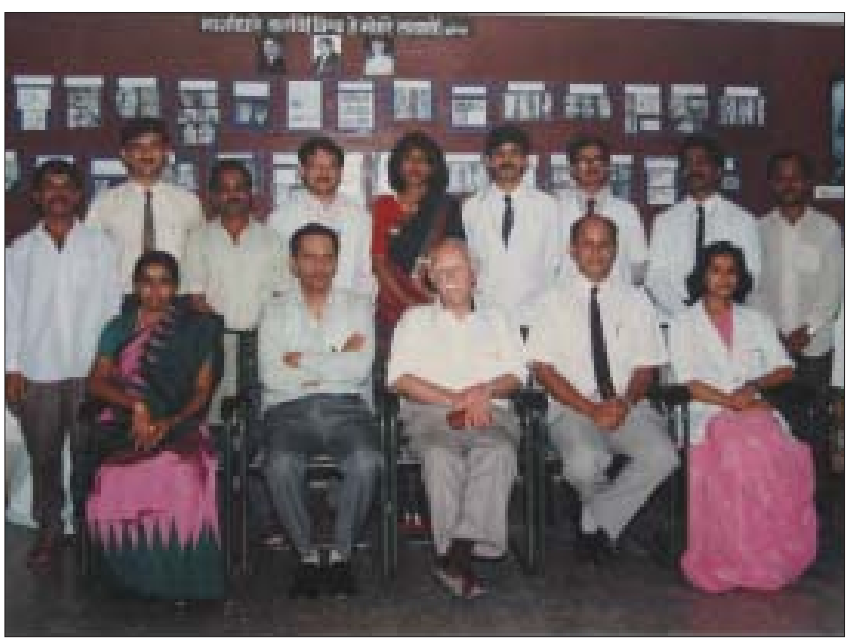

Figure 3: Mr. M. N. Tempest with the department

my chief surgeon and superintendent, I was permitted to visit the department of plastic surgery of K. E. M. hospital and take training under Dr. Charles Pinto even though I was working at Sion Hospital. Hence, whatever

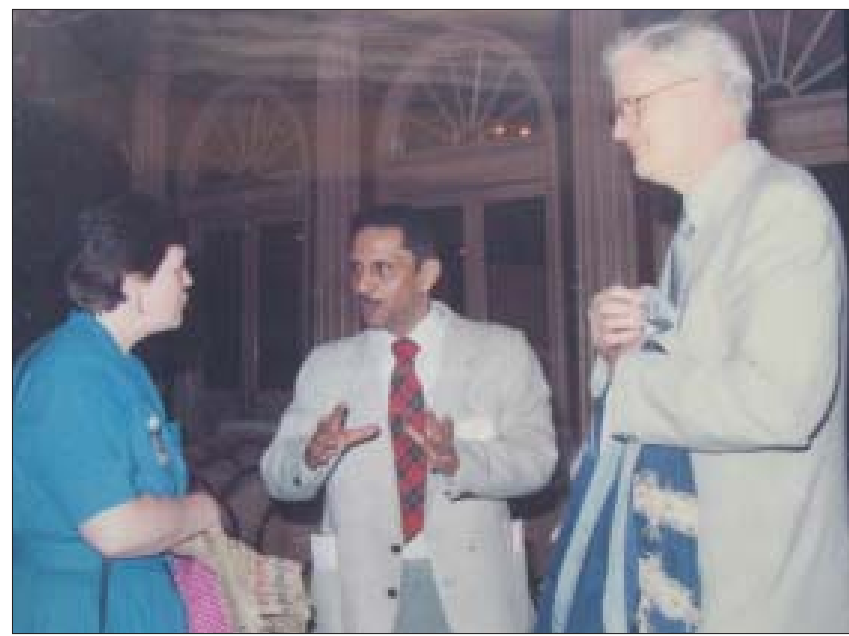

Figure 4: Mr. A. C. H. Watson with Dr. R. L. Thatte at the Royal College of surgeons of Edinburgh function

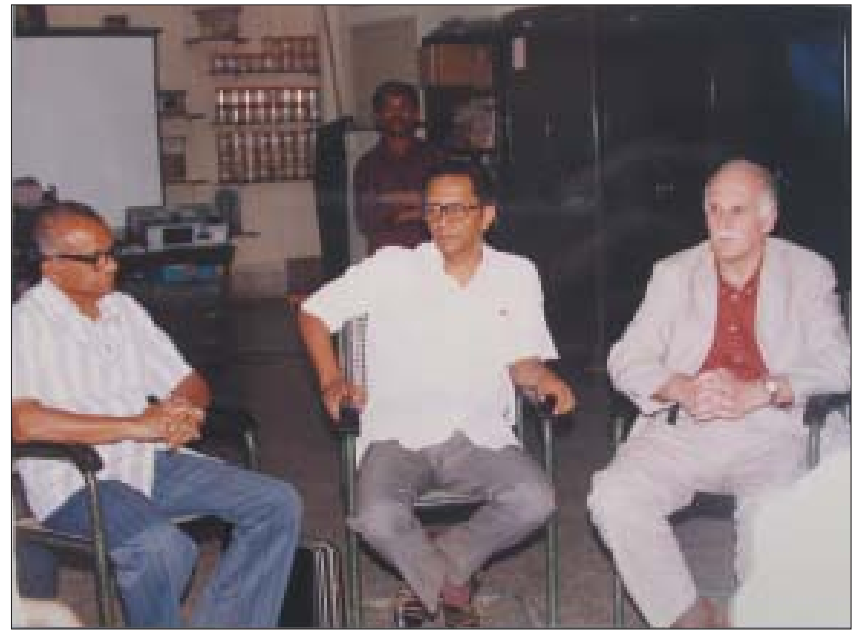

Figure 5: Drs. A. D. Dias and R. L. Thatte with Mr. Phil Sykes

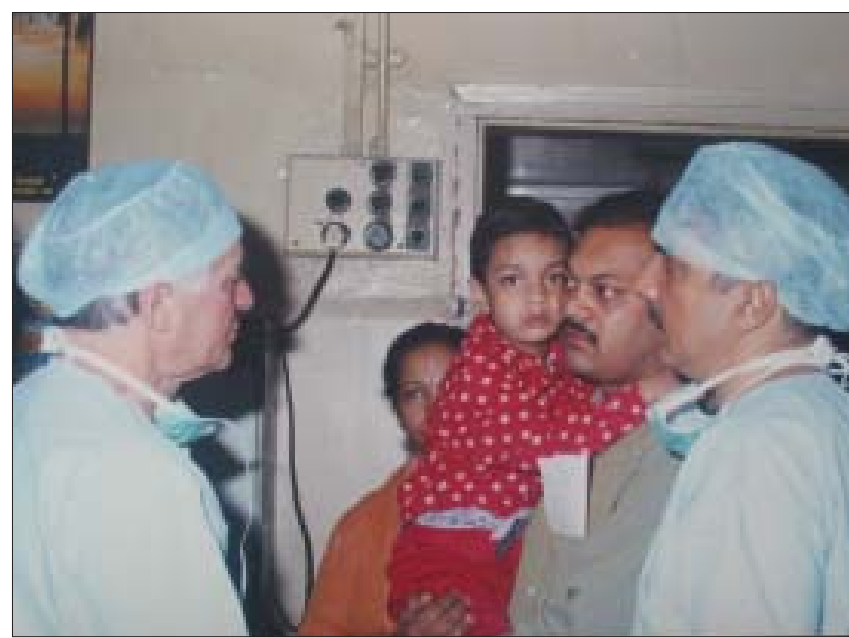

Figure 6: IT Jackson with Mukund Jagannathan—current head

I saw and discussed at K. E. M. Hospital, I could immediately put into practice at Sion. I did my first Johansson's urethroplasty in the afternoon after attending Dr. Johansson's lecture at K. E. M. Hospital in 
the morning! There were hardly any bureaucratic problems in those days. I was able to obtain several plastic surgery instruments, journals (like the British Journal of Plastic Surgery and the Plastic and Reconstructive Surgery) and books. Hence, when we started our Department of Plastic surgery, we already had good infrastructure.

With the help of our superintendent, the senior registrars at Sion Hospital were straight-away catapulted to the status of part time surgeons and Hon. Surgeon. As I was working in the employees state insurance scheme (E.S.I.S.) I used to see several cases of Hand injuries and deformities which were mostly "iatrogenic problems" in the sense that they were not properly treated initially. We arranged to get these patients with hand injuries referred to us primarily at least on one day in the week. These cases were traditionally treated by orthopaedic surgeons. In this work we received excellent cooperation from physiotherapy and occupational therapy departments.

We also noticed that facial and mandibular fractures were treated by dentists. This was odd. Hence we arranged to have faciomaxillary cases referred to us on any day or time. We also did a lot of planning and ground work for developing a special burns unit. But this section went to the general surgery department due to some administrative problems. We also encouraged the development of micro surgery with the purchase of a new microscope for our department.

We encouraged original work and innovation. We had a practice of not accepting thesis of M.Ch. (Plastic) unless the work was original. The students were of course guided by their teachers in this work. Hence several original articles were published in the British Journal of Plastic Surgery and others by several of our staff. In this work we received excellent co-operation from the departments of basic sciences viz. anatomy, physiology, biochemistry and also from our artist department. (Mr. Desai, Mr. Parshuram and others).

Our initial 7 students passed their M.Ch. examinations at the first attempt and the trend was usually maintained. We had established the "Glaxo award" for the best original research work in plastic surgery (through the medical welfare trust). Our department won the award on almost all occasions.
Several original work was done by our staff and published in reputed journals or presented in conferences. Some of them are:

1. Immediate urethroplasty for acute retention following chronic stricture of the urethra.

2. Reconstruction with the use of a sheath of fine stainless wire mesh.

3. Heterotopic para-articular ossification of the elbow with soft tissue contracture anteriorly in burns and its successful management.

4. Bipedicle flaps in the correction of burns contracture, obviating the need for a splint.

5. True endaural approach to the temporomandibular joint, leaving a barely visible scar.

6. The SEPA flap, which increased and revolutionized the options for coverage of hand defects.

7. The posterior auricular (PARAS) flap for facial defects, ensuring a hidden donor site.

8. Anthropometry of the Indian nose, setting standards for the Indian population.

9. The reverse dermis or turnover flap, used for management of difficult defects. This flap revolutionized the management of such problems at that particular frame of time.

10. Venous flaps-proved by both clinical and isotope studies, they questioned the existing norms and the basis of blood circulation as we knew it. We had established a type of record keeping (card system) photographic slide system, which were very helpful in writing papers.

We received excellent co-operation from all our medical, plastic, nursing, anaesthetic and other ancillary staff. We all worked as one big happy family.

I would especially like to mention the tremendous contribution (both nationally and particularly internationally) of my assistant, Dr. Ravin Thatte.

Thus even though we were a very young department, we managed to make a good impression both on the national and to some extent on the international scene in a short time.

The Department evolves.

Dr. A. D. Dias

It is interesting that our Guru Dr. Dias ends his narrative with the words the department evolves, for evolve it 
did. I joined the department in November 1984 just when Dr. Dias retired and Dr. Ravin Thatte took over and was witness to what I think was the golden era of this department. Dr. L. D. Dhami our first M.Ch. student to have completed the course had just left for UK. However other stalwarts like Dr. U. A. Patil, Dr. D. L. Patil, Dr. A. D. Yelikar and P. C. Chhajlani were very much there. Later I was followed by Drs. S. K. Purohit and S. M. Kumta. Dr. S. U. Prasad was the kingpin. He 'managed' the whole lot through thick and thin. Though officially retired, Dr. Dias continued to attend the OPD and take post graduate clinics and we got a taste of the famous 'Dias' grilling which our Lecturer Dr. S. U. Prasad had told us so much about. According to Dr. Prasad the first 'beneficiary' was Dr. A. Gopalkrishna and the second was Dr. Prasad himself while they prepared to appear for their M.Ch. exams. It felt horrible at the time but looking back it was the most formative influence on us. We were questioned constantly and in the most basic ways which forced us to go back to basics and moulded a way thinking which serves us well till today. His most dreaded question say on a chronic non healing ulcer used to be 'What is your diagnosis, man?' to which he would add an aside 'any body can put a graft!' thus completely puncturing our surgeon's egos and forcing us to think.

The then Dean at KEM Hospital Dr. G. B. Parulkar disallowed my transfer to Sion on the grounds that I needed to complete my general surgery registrar post. I found this very unfair and annoying at the time but it turned out to be a blessing in disguise. My then chief and teacher Prof. A. B. Samsi who was one the most supportive teachers I know told me to use the time doing research and gave me free time to do experimental work. Dr. Ravin Thatte was my guide and teacher for M.Ch. and he showed me an article by Prof. Se Min Baek from Korea on venous flaps in dogs. I decided to test this hypothesis in the KEM dog lab, which had been established by the legendary Dr. P. K. Sen, with the support of Dr. Samsi and permission of the chief Dr. R. A. Bhalerao. It was a fascinating journey and I had my first exposure to high quality photography when Dr. RLT rubbished the amateur pictures taken by me and sent the inimitable 'Parshu' [Figure 2] to shoot a full series. His style, quality and attention to detail was a revelation which was to create a deep impression on all those who worked for the department. In fact the influence of RLT and Parshu on our methods of presentation-especially in terms of quality of pictures and clarity of thought process continues unabated. The adversity of having to continue in general surgery was thus converted into an advantage by completing a most remarkable series of experiments on venous flaps which eventually became my thesis and the basis for several papers which won international acclaim.

Although replantations were started as early as $1980 / 81$ by Dr. A. Gopalkrishna, Dr. S. U. Prasad was instrumental in tying to actually start serious clinical microsurgery. He too started doing reimplants early on with Dr. L. D. Dhami and I remember his free flap (first web of foot to first web of hand) on Gudi Padva day in 1985 after completing the pooja in ward 36 . We struggled with sub optimal instruments and a fairly poor microscope but the flap was done and the seed was sown. Eventually with me back from the UK with microsurgery training and Drs. Prashant Govilkar and Samir Kumta also having obtained training in Italy and Hong Kong we started the free flap programme in earnest and over the years many people got trained in the department and abroad, including Dr. Milind Wagh who so ably handles this aspect in the department today. The contributions of Dr. Mrs. Jagtap and especially Dr. Mrs. LD Naik from anaesthesia is worthy of very special mention for without their support in OT as well as with the recovery room this venture would not have taken off. Dr. Ravin Thatte was instrumental in inculcating a sense of discipline and bringing in things like seminars, journal club, planning round and interestingly enough compulsory anatomy dissections - these not only helped us to be better surgeons but also led to the development of the plastic surgical anatomy museum. Under his stewardship we evolved into a full fledged unit with a wide clinical repertoire and excellent teaching and research programme. Moreover it was perhaps one of the few units in the country then where intellectual freedom was complete. One could ask any question and make any suggestion regarding treatment as long as it was supported by sound references. This was perhaps the single most important factor in the intellectual flowering that followed. The papers published from this unit are a testimony to that spirit.

Throughout this period we shared a very 'special relation' with the orthopaedic department led by Dr. N. S. Laud. We argued and fought constantly at the junior level but we also put through some remarkable work jointly in terms of volume and diversity. This department was one 
of the first to recognize the value of joint work and joint clinics (lower limb trauma-Dr. D. L. Patil briefly served as a specialized fellow - and Hand Injury, the later with the OT and PT departments as well) and many innovations in early flap cover, newer types of flaps and looking at fracture union as the end point rather than flap healing was made possible because of the vision showed by Dr. R. L. Thatte and Dr. N. S. Laud.

The joint clinics extended to the dental and dermatology faculty as well with the willing co operation of Dr. Shanbhag from dental surgery. We had the joint cleft clinic as well as the maxillofacial injury clinic together. In his company we learnt some valuable lessons about occlusion and orthodontia. He was also an excellent guide on the pubs of Edinburgh and the merits of single malt and took a 'special clinic' for me when he heard that I was getting a job in Edinburgh. I also recollect the valuable teamwork which continued with his successor Dr. Hemant Dhusia. With Dr. Mrs. Hema Jerajani we established the joint dermatoplastic clinic where too this concept of team work has proved very useful.

Since 1981 the department was fortunate to have very regular contacts with Units abroad in UK and also with Australia. Dr. Ravin Thatte's contacts with two successive editors Michael Tempest [Figure 3] and ACH Watson [Figure 4] were instrumental in creating this situation, Mr. Philip Sykes too has been a great friend [Figure 5]. Mr. Tempest published our first paper abroad and then there was a deluge of papers from what was perhaps one of the most creative units in Indian History. We were also blessed to be in regular contact with Mr. I. T. Jackson [Figure 6] one of the living legends in plastic surgery today.

Dr. S. N. Deshpande trained in Adelaide. He joined again for some in 1990/91 and started some craniofacial work. Dr. Shrirang Purohit started oculoplastic work. Dr. Nitin Mokal trained in Taiwan and Singapore and then came back and started regular craniofacial surgery, a subspecialty hitherto not regularly available in our institute. This was 1993, at this point in time we were truly a very integrated and complete unit with most sub specialities of plastic surgery being done and done well under one roof and in the most dynamic unit at that time. Many alumni today hold important positions. Dr. Mukund Thatte is editor of the Indian Journal of Plastic Surgery and president of the Indian Society of cleft lip palate and craniofacial anomalies (ISCLP and CA); Dr. Jyotsna Murthy heads one of the biggest cleft centres in the country and is Hon. Secretary ISCLP and CA, Dr. H. V. Satish runs a plastic unit in Mysore as do Dr. Ketu Patel in Ahmedabad and Parag Sahasrabudhhe in Pune, Dr. B. B. Nayak is perhaps one of the most dynamic plastic surgeons in his home state of Orissa and has effectively introduced regular microsurgery there. Dr. Shailesh Ranade and Dr. Neeta Patel along with Dr. Arun Sheth are successful consultants in Mumbai, Dr. Dean CunhaGomes is a consultant in Bahrain and Dr. Pankil Shah is heading a unit in Valsad. Dr. Suyash Patankar heads a unit in Thane while Alexander George is well settled in Kuwait, Dr. Charudutt Chowdhary is a specialised cancer reconstruction consultant at Bombay Hospital. There are inevitably names that are missed for which I apologise in advance.

Thing have since moved on. Due to unfavourable personnel policies in the municipal corporation at that time, many of us had to move on for personal and financial reasons. Dr. R. L. Thatte retired, but then Dr. Mukund Jagannathan appeared on the scene and in a remarkable takeover has managed to fill in the rather large shoes which had been vacated. In his words "for me it was culture shock, coming from a relatively laid back unit, to a very busy one. In order to keep the craniofacial work alive, I had decided to spend some time with Ian Jackson, which was instrumental in surmounting the invisible barrier which everyone must cross, in order to perform supra major surgery. Dr. Jackson continues to be a constant supporter of the department in several ways and spends time in the unit every time he comes to India [Figure 6]. Being an 'outsider' I was a little worried about acceptance in the stream of things, but in the inimitable fashion laid down by ADD and RLT, it was easy to slip into the mainstream with minimal effort".

With the very able support of Dr. Milind Wagh they have together tried and managed to retain most of the specialized work of their predecessors and in fact have increased in reach and sophistication. For example the data now being presented in microsurgery in national meetings makes us feel proud about the volume and quality of work being carried on. The same can be said about sophisticated cleft and craniofacial work being carried out. Nothing is constant in this world; neither is our unit the exception to this rule; however the solid foundation laid by Dr. Dias and Dr. R. L. Thatte has created 
an edifice which will evolve successfully with changing times. I hope someone 25 years from now is able to write an equally upbeat continuation of this story. Only time will tell.

\section{Milestones in the department}

1979:

- Formal separation of department from general surgery, Dr. A.D. Dias assumes responsibility as the chief. $\mathrm{MCI}$ recognition given for 5 years

- Appointment of the first full time tutor.

1980: Appointment of a dedicated photographer (Parshuram Pangerkar)

1981: First M.Ch. Student registered.

1983:

- First successful student Dr. LD Dhami graduates

- De-epithelialised turnover flap makes national and international waves

1984

- First successful replant
- Dr. Dias retires; Dr. Thatte takes over as chief

1985: First successful free flap performed

1987: Cephalic venous flap performed and published

1990: First successful craniofacial procedure perfomed.

1995: Dr. Thatte awarded the FRCS (Edin) advisory hominem

1998: Dr. Thatte retires; Dr. Mukund Jagannathan takes over as chief.

2001: Formal MCI re-recognition for the department retrospectively (This had to be done as the 'Education section' in the college office 'forgot' to renew it after the first five years.)

2002: Shifting to a dedicated operation theatre complex.

Editorial Comment: The department celebrated its silver jubilee last year. It was therefore appropriate to chronicle its history in this issue in our regular history column.

\section{ANNOUNCEMENT}

\section{$6^{\text {th }}-8^{\text {th }}$ October, 2006: Rome (Italy)}

"State of art in liposculpture, $\mathbf{3 0}$ years from its invention"

$28^{\text {th }}$ Meeting of Up-dates of the Italian Society of Cosmetic Surgery (SICE) and in collaboration with the Italian

Society of Liposuction (SIL)

Language: Italian / English

E-mail:info@societaitalianachirurgiaestetica.it

Further Information:

Italian Society of Cosmetic Surgery

Dr. Giorgio Fischer, Rome, Via Della Camilluccia ${ }^{\circ} 643$, Italy

Phone: +39 (0) 636304792

Fax: +39 (0) $636303204-36304165$ 